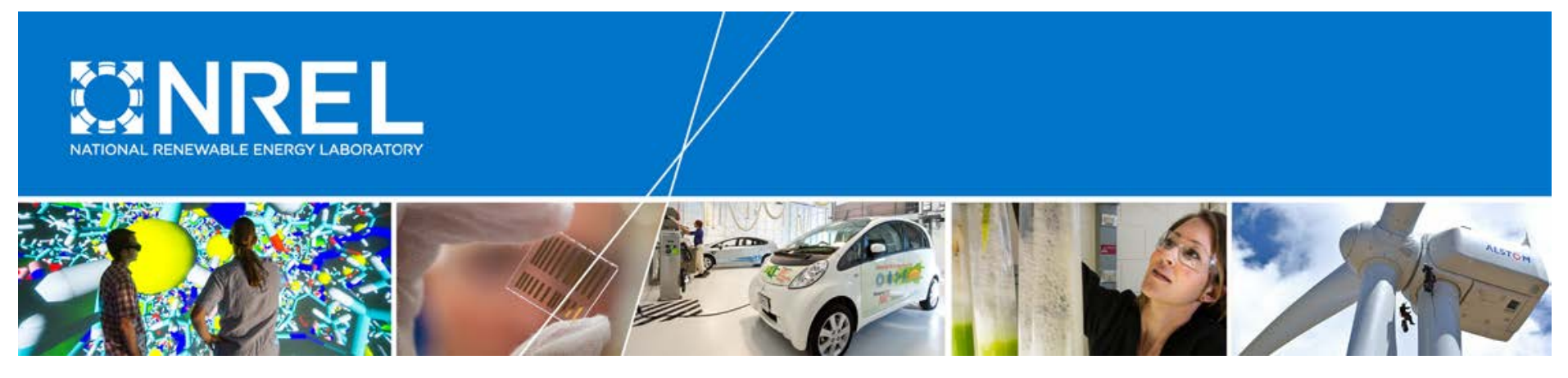

\title{
Analytical Modeling of a Novel Transverse Flux Machine for Direct Drive Wind Turbine Applications
}

\section{Preprint}

Ilftekhar Hasan, ${ }^{1}$ Tausif Husain, ${ }_{1}^{1}$ Md Wasi Uddin, ${ }^{1}$ Yilmaz Sozer, ${ }^{1}$ Iqbal Husain, ${ }^{2}$ and Eduard Muljadi ${ }^{3}$

${ }^{1}$ University of Akron

${ }^{2}$ North Carolina State University

${ }^{3}$ National Renewable Energy Laboratory

To be presented at the IEEE Energy Conversion Congress and Exposition

Montreal, Canada

September 20-24, 2015

NREL is a national laboratory of the U.S. Department of Energy Office of Energy Efficiency \& Renewable Energy Operated by the Alliance for Sustainable Energy, LLC

This report is available at no cost from the National Renewable Energy Laboratory (NREL) at www.nrel.gov/publications.

Conference Paper

NREL/CP-5D00-64745

August 2015

Contract No. DE-AC36-08GO28308 


\section{NOTICE}

The submitted manuscript has been offered by an employee of the Alliance for Sustainable Energy, LLC (Alliance), a contractor of the US Government under Contract No. DE-AC36-08GO28308. Accordingly, the US Government and Alliance retain a nonexclusive royalty-free license to publish or reproduce the published form of this contribution, or allow others to do so, for US Government purposes.

This report was prepared as an account of work sponsored by an agency of the United States government. Neither the United States government nor any agency thereof, nor any of their employees, makes any warranty, express or implied, or assumes any legal liability or responsibility for the accuracy, completeness, or usefulness of any information, apparatus, product, or process disclosed, or represents that its use would not infringe privately owned rights. Reference herein to any specific commercial product, process, or service by trade name, trademark, manufacturer, or otherwise does not necessarily constitute or imply its endorsement, recommendation, or favoring by the United States government or any agency thereof. The views and opinions of authors expressed herein do not necessarily state or reflect those of the United States government or any agency thereof.

This report is available at no cost from the National Renewable Energy Laboratory (NREL) at www.nrel.gov/publications.

Available electronically at SciTech Connect http:/www.osti.gov/scitech

Available for a processing fee to U.S. Department of Energy and its contractors, in paper, from:

U.S. Department of Energy

Office of Scientific and Technical Information

P.O. Box 62

Oak Ridge, TN 37831-0062

OSTI http://www.osti.gov

Phone: 865.576.8401

Fax: 865.576.5728

Email: reports@osti.gov

Available for sale to the public, in paper, from:

U.S. Department of Commerce

National Technical Information Service

5301 Shawnee Road

Alexandria, VA 22312

NTIS http://www.ntis.gov

Phone: 800.553 .6847 or 703.605 .6000

Fax: 703.605.6900

Email: orders@ntis.gov 


\title{
Analytical Modeling of a Novel Transverse Flux Machine for Direct Drive Wind Turbine Applications
}

\author{
Iftekhar Hasan $^{(1)} \quad$ Tausif Husain $^{(1)} \quad$ Md Wasi Uddin $^{(1)} \quad$ Yilmaz Sozer $^{(1)} \quad$ Iqbal Husain $^{(2)} \quad$ Eduard Muljadi $^{(3)}$ \\ (1) ECE Department \\ The University of Akron \\ Akron, USA \\ (2) ECE Department \\ North Carolina State University \\ Raleigh, USA \\ (3) National Renewable Energy \\ Laboratory \\ Golden, CO, USA
}

\begin{abstract}
This paper presents a nonlinear analytical model of a novel double sided flux concentrating Transverse Flux Machine (TFM) based on the Magnetic Equivalent Circuit (MEC) model. The analytical model uses a series-parallel combination of flux tubes to predict the flux paths through different parts of the machine including air gaps, permanent magnets (PM), stator, and rotor. The two-dimensional MEC model approximates the complex three-dimensional flux paths of the TFM and includes the effects of magnetic saturation. The model is capable of adapting to any geometry which makes it a good alternative for evaluating prospective designs of TFM as compared to finite element solvers which are numerically intensive and require more computation time. A single phase, 1 $\mathrm{kW}, 400 \mathrm{rpm}$ machine is analytically modeled and its resulting flux distribution, no-load EMF and torque, verified with Finite Element Analysis (FEA). The results are found to be in agreement with less than $5 \%$ error, while reducing the computation time by 25 times.
\end{abstract}

Keywords - Transverse flux machine (TFM), nonlinear, magnetic equivalent circuit (MEC), magnetic saturation, flux concentrating, finite element analysis (FEA),

\section{INTRODUCTION}

Transverse Flux Machines (TFM) have flux paths that are transverse (perpendicular) to the rotating motion of the rotor and that of current [1]. TFM offers high torque and power density [2] which makes it lucrative for low speed and high torque applications. Flux concentrating TFM is well suited for applications such as vehicle propulsion and wind turbines [3]. Flux concentrating topologies creates very high torque-densities, which can be over four times higher than in conventional high torque machines [4]. Leakage inductance, high torque ripple, poor power factor and complicated manufacturing process [1] are some of the negative attributes that has restricted the industrial applications of TFM. However, recent advancements in power electronic converters and three-dimensional (3D) finite element analysis (FEA) software tools has led to the development of better design and analysis procedure for complex $3 \mathrm{D}$ geometries of TFM along with new control schemes for torque ripple minimization.

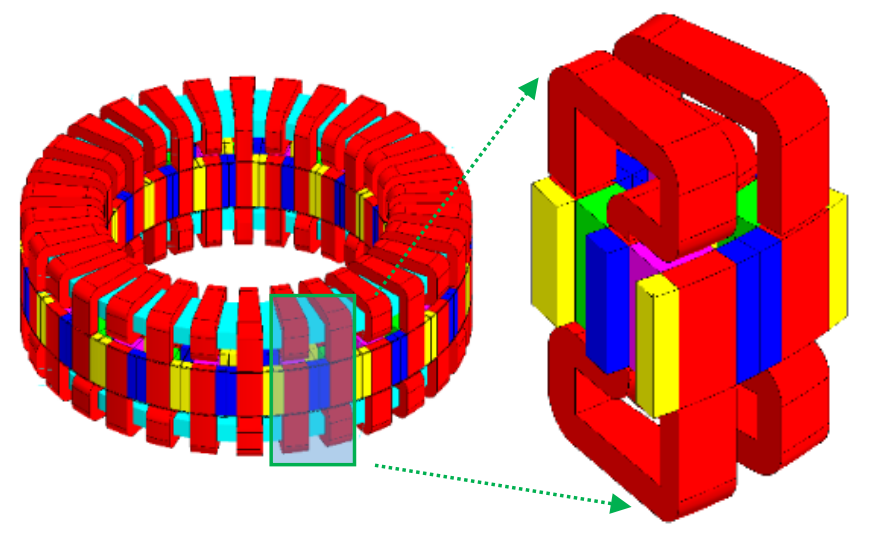

Fig. 1(a). 3D model of the proposed PMTFM

Fig. 1(b). One pole pair of the proposed PMTFM

Accurate prediction of the parameters and characteristics of electromagnetic devices with complex geometry and high saturation using advanced numerical methods like finite element solvers are time consuming process that requires significant computational resources. Altering design parameters (machine dimensions, current density) in FEA requires the model to be reconstructed and re-meshed. Taking these factors into account, FEA is not ideal to be used during the initial design stage of the electric machine. A faster nonlinear analytical model capable of producing similar results to the FE solvers is essential to facilitate faster analysis of preliminary TFM design.

The magnetic equivalent circuit (MEC) model is a common analytical tool which analyses the performance of electric machines by considering the machine's material characteristics [5]-[8]. Several analytical models have been developed for different TFM configurations. In [9] magnetic charge and magnetic imaging techniques were used to predict the flux and no load EMF for a single sided surface mounted PMTFM with 15\% error. The MEC modeling concept has been applied to different TFM configurations in [10]-[14] for predicting air gap flux density with less than $10 \%$ error.

In this paper, a novel double sided flux concentrated TFM with new stator and rotor topology is presented. The 3D model for the quasi-U core permanent magnet (PM) TFM is 
shown in Fig. 1. The analytical modeling of such TFM is a sophisticated task as these machines have 3D flux paths [2]. The presence of magnetic flux guides in the rotor increases the complexity of the MEC model. The flux paths vary with dimensions, which implies that the analytical model should be tailored accordingly.

The novel TFM structure and its operating principle is explained in Section II. The MEC model for a TFM pole pair and its implementation to calculate flux, no load EMF and torque is discussed in Section III. The air gap and leakage flux path modeling is illustrated in Section IV. A nonlinear algorithm for considering the effects of magnetic saturation is developed in Section V. In section VI, the results for flux linkage, EMF and torque obtained using MEC model are verified with 3D-FEA simulations.

\section{TRANSVERSE FLUX MACHINE STRUCTURE}

The PMTFM has a modular structure with ring windings, and uses non-rare-earth ferrites. A very important advantage of the proposed topology, which doesn't exist in conventional machines, is the modularity, which means that each phase is an independent module. This feature makes the machine very attractive for mass production, since a wide range of power can be covered by placing an adequate number of modules together. In order to obtain a three phase motor, these modules are axially stacked with the rotor PMs having an angular displacement of 120 electrical degrees to each other.

\section{A. Rotor}

Each phase module consists of a disc-shaped rotor with PMs sandwiched between the rotor cores. The magnets act as flux guides. The ratio of the magnetic surface area to the pole surface area determines the focusing factor. The magnet orientations are such that the two magnets are either pointing to each other or pointing away from each other. The adjacent rotor cores are arranged to align with the stator cores to the left, middle and the right, respectively, as shown in Fig. 2 to close the magnetic circuit. The flux produced by the permanent magnets concentrates at the bottom of middle side stator pole. The stator pole beside the PM have different width to avoid excessive saturation in the stator core. The rotor pole have the same width to match the stator. Since the rotor speed is low, centrifugal force created when the rotor rotates is not very high.

\section{B. Stator}

The stator consists of two alternate quasi-U cores with double active sides facing the rotor via two axial air gaps and two ring windings in the upper and lower stator slots. The stator orientation minimizes the exposed windings to reduce the leakage fluxes. The double sided windings maximize the stator core utilization and make the machine highly fault tolerant.

An illustration of the concept machine is given in Fig. 1. In this paper, one module unit is designed and optimized to be used for direct drive wind turbine applications. The geometrical parameters along with the design specifications and restrictions are indicated in Fig. 2 and their values are summarized in Table I.

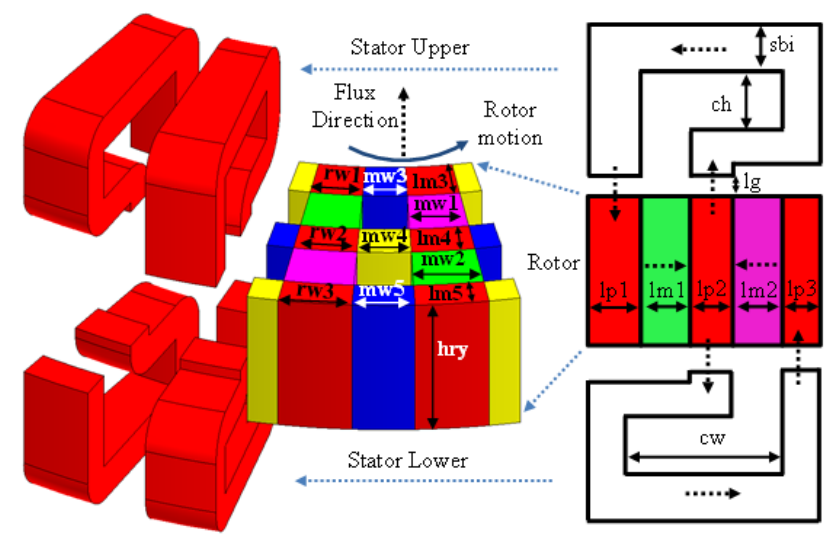

Fig. 2. Flux path in stator transverse to rotor rotation along with rotor and stator dimensions

TABLE I. TFM motor parameters

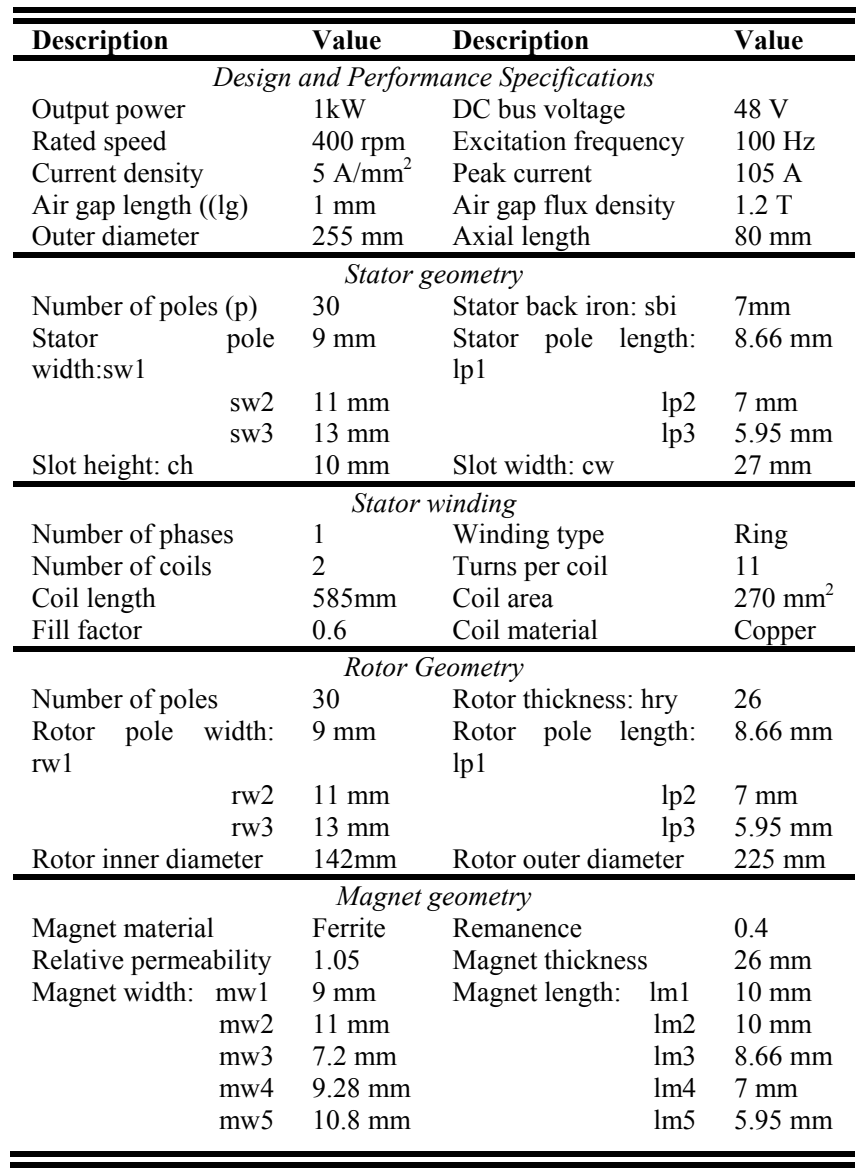

\section{MAGNETIC EQUIVALENT CIRCUIT}

The MEC approach is a powerful tool for electric machine design and has been presented in great detail in [15]. It is a numerical method for the analysis of the 
nonlinear magnetic field in electrical machines for steadystate and dynamic conditions [16]. The MEC model allows the geometry of a double sided flux concentrated PMTFM to be incorporated into a generic structure which makes it solvable for any specific geometry. Volumetric tubes are used to model the paths of magnetic flux through the machine. Discretization of the flux into volumetric flux tubes and defining them as reluctance elements which are a function of the geometry and permeability creates a magnetic circuit that can be solved by mesh analysis using the electrical circuit matrix method [17].

For this model, separate reluctances are used to represent the rotor poles, rotor back iron, stator poles, stator back iron and air gap. The current carrying coil conductor and the permanent magnets are modeled as mmf. The polarity of the permanent magnet alternates with changing rotor position due to different orientations of the magnets embedded in the rotor. Hence calculation for the flux at every rotor position must be handled carefully. Electromagnetic characteristics of the TFM are the same and repetitive in every one pole pair. Therefore, the magnetic equivalent circuit of one pole pair is considered for the analytical model as shown in Fig. 3. As in FEA, magnetic saturation and leakage are obtained directly from knowledge of the material characteristics and machine geometry based reluctance network in the MEC approach. In contrast to the FEA technique, the nonlinear equations that are solved at each step in the MEC model are less computationally intensive, thus making it ideal to be used in design optimization, control and modeling.

The basic equation that governs each element of the MEC model [18], is

$$
F=\varphi R
$$

where $\phi, R$, and $F$ are the flux, reluctance and $\mathrm{mmf}$, respectively, and

$$
R=\frac{L}{\mu_{r} \mu_{o} A_{c}}
$$

where $\mu_{r}, \mu_{o}, A_{c}$, and $L$ are the relative permeability, the permeability of free space, the cross-sectional area, and the length of each element, respectively.

\section{A. Modeling MMF sources}

Each stator winding is modeled as an MMF source $F_{c}$

$$
F_{C}=N I
$$

where $I$ is the phase current and $N$ is the number of turns. Each PM is modeled as an MMF source $F_{M}$ in series with an internal reluctance $R_{M}$ [23] where

$$
\begin{gathered}
R_{M}=\frac{L_{M}}{\mu_{r m} \mu_{o} A_{M}} \\
F_{M}=\frac{B_{r} L_{M}}{\mu_{r m} \mu_{o}} \\
A_{M}=H_{M} L_{A}
\end{gathered}
$$

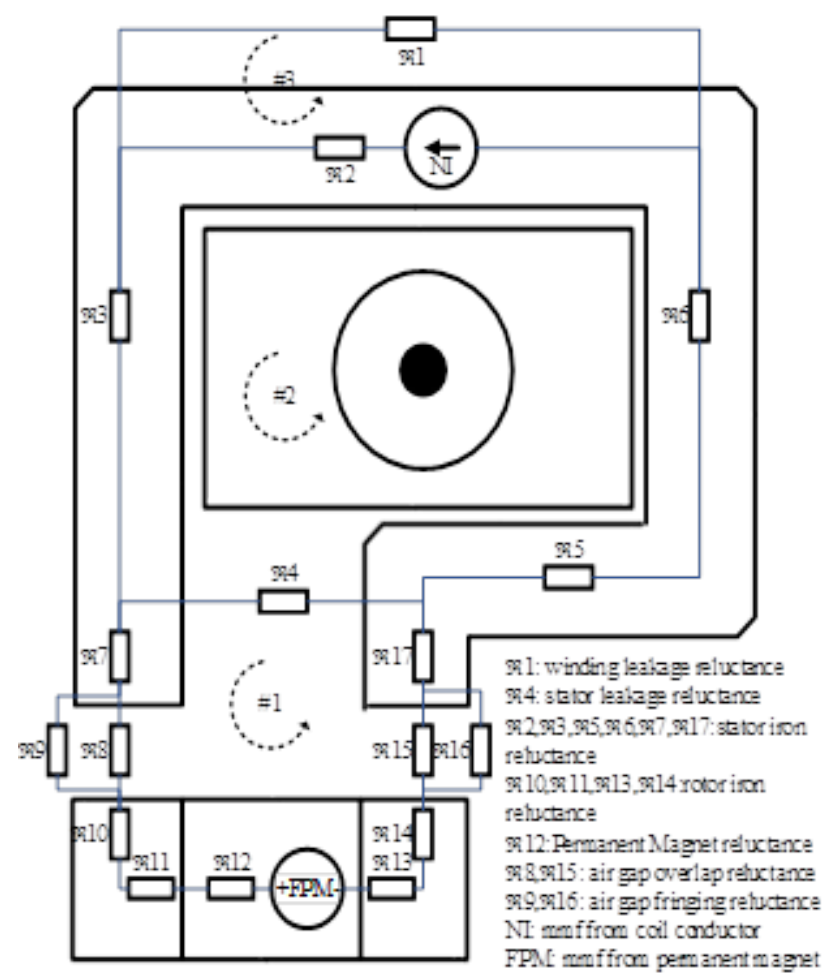

Fig. 3. MEC model for one TFM pole

$\mu_{r m}$ and $B_{r}$ are the recoil permeability and remanence, respectively. $A_{M}, L_{M}, H_{M}$, and $L_{A}$ are the cross-sectional area and thickness of the magnets in the direction of magnet field orientation, length of the magnets in the radial direction, and the axial length of the core, respectively.

\section{B. Flux linkage} by

The total flux linking the stator winding $\lambda(\theta)$ is obtained

$$
\begin{aligned}
& \varphi(\theta)=\frac{F_{C}+F_{M}}{R_{T}(\theta)} \\
& \lambda(\theta)=N \varphi(\theta)
\end{aligned}
$$

where $\theta$ is the rotor position, $R_{T}$ is the total machine reluctance including the rotor, stator, air gap and leakages. The flux entering the core of the TFM is only a part of that present in the air gap. The remaining part of the flux in the air gap is the armature leakage [19]. Due to armature flux leakage, not all the flux produced by the magnets enters the core and actually links the coil [20]. The modeling for the air gap and leakage fluxes are discussed in detail in Section IV.

\section{C. $E M F$}

The no load EMF generated by the TFM can be derived from the flux through the core, which is calculated in (7). The EMF $e(\theta)$ is given by

$$
e(\theta)=N \frac{\partial \varphi}{\partial \theta}
$$




\section{Torque}

The torque produced in any electrical machine is given by the rate of change of magnetic coenergy of its winding with respect to position [21]. Here the MEC model has been used along with the virtual work method [22] to predict the torque in electric machines using the air gap flux information for changing rotor position. The virtual work method states that for a rotating machine, torque is given by

$$
T=\frac{\partial W^{\prime}(\theta, i)}{\partial \theta}
$$

where $W^{\prime}$ is the magnetic co-energy stored within the machine which is obtained by

$$
W^{\prime}(\theta, i)=\int_{i=0}^{I} \lambda(\theta, i) d i
$$

where $\lambda$ is the flux linkage in the coil. It is easier to keep the current constant in the MEC model rather than the flux linkage. Thus calculating torque using the co-energy method is preferred here.

\section{AIR GAP RELUCTANCE}

A crucial component of the MEC is the flux tube in the air gap as shown in Fig. 4. The air gap is the primary location of energy storage in the machine. Establishing a closed form expression for air gap reluctance is difficult because the rotor changes position relative to the stator. Therefore, tube dimensions change as a function of rotor position. Tube reluctance $R_{\text {airgap }}$ which is a function of tube length $L$, cross-section area $A_{c}$ and magnetic permeability $\mu$ inside the tube [15] is given by

$$
\begin{gathered}
R_{\text {airgap }}=\frac{L}{\mu_{0} A_{c}(\theta)} \\
d R=\frac{d x}{\mu A_{c}(\theta)} \\
R=\int \frac{d x}{\mu A_{c}(\theta)}
\end{gathered}
$$

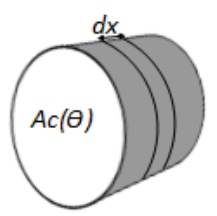

Fig. 4. Flux tube.

In most cases, the tube volume between the planes has a non-uniform length or cross-sectional area. For tubes with non-uniform area, it is convenient to discretize the volume into differential tube reluctances as shown in (13) where $d x$ is the differential tube length, and $A_{c}(\theta)$ is the crosssectional area which must be derived analytically. Integration of the differential reluctance over the entire length of the tube provides the tube reluctance as shown in (14). Different reluctances that are included in the air gap model: variable air gap reluctance, complete and partial pole overlap fringing reluctance, stator core fringing reluctance and winding leakage reluctance.

\section{A. Variable air gap reluctance}

The variable air gap reluctance across the overlapping poles have two components depending on the position of the rotor.
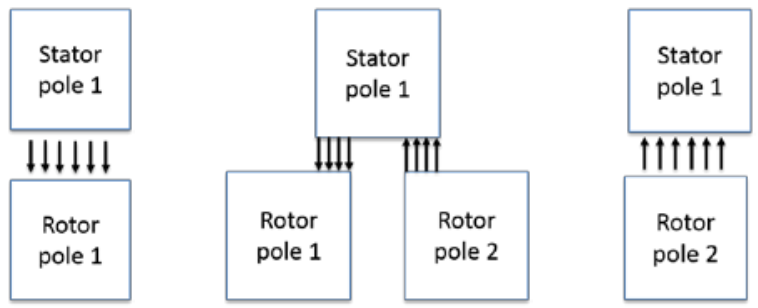

Fig. 5. Stator and rotor pole orientations

The same stator pole may see two different rotor poles with alternate flux paths as the rotor position changes as shown in Fig. 5. The net flux path is the sum of the two flux paths resulting from different overlapping rotor poles.

\section{B. Partial pole overlapping fringing reluctance}
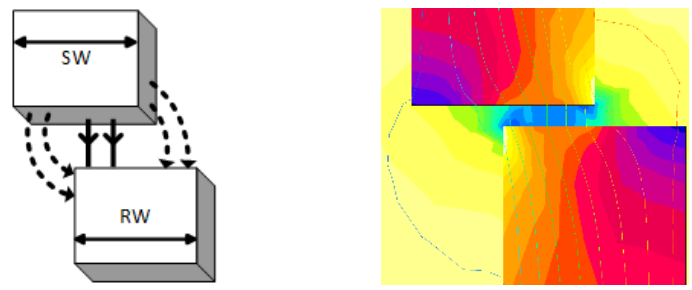

Fig. 6. Partial pole overlapping fringing leakage (left) compared with the FEA flux paths in Flux2D (right).

When there is partial overlap between the rotor and stator poles as shown in Fig. 6, the fringing field is portrayed as $90^{\circ}$ wedge curved flux lines [21] coming out from the face of one pole and entering the side of the overlapping pole, as calculated by

$$
R_{\text {poverlap } 1}=\frac{2 \pi(\operatorname{shaft}+\operatorname{lp} 1)}{8\left(p \mu_{o}\right) \operatorname{shaft}(\operatorname{lp} 1)}
$$

$$
R_{\text {poverlap } 2}=\frac{2 \pi(\operatorname{shaft}+\operatorname{lp} 1+\text { magin }+l p 2)}{8 \mu_{o} p(\operatorname{shaft}+\operatorname{lp} 1+\operatorname{magin}) \operatorname{lp} 1}
$$

\section{Complete pole overlapping fringing reluctance}

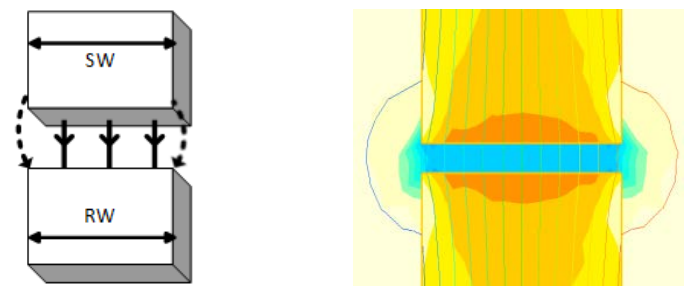

Fig. 7. Complete pole overlapping fringing leakage (left) compared with the FEA flux paths in Flux2D (right). 
When there is a complete overlap between the rotor and stator poles as shown in Fig. 7, the flux tube is approximated by an $180^{\circ}$ semicircle [21], as calculated by

$$
\begin{aligned}
& R_{\text {coverlap } 1}=\frac{2}{R_{\text {poverlap } 1}} \\
& R_{\text {coverlap } 2}=\frac{2}{R_{\text {poverlap } 2}}
\end{aligned}
$$

\section{Stator core fringing reluctance}
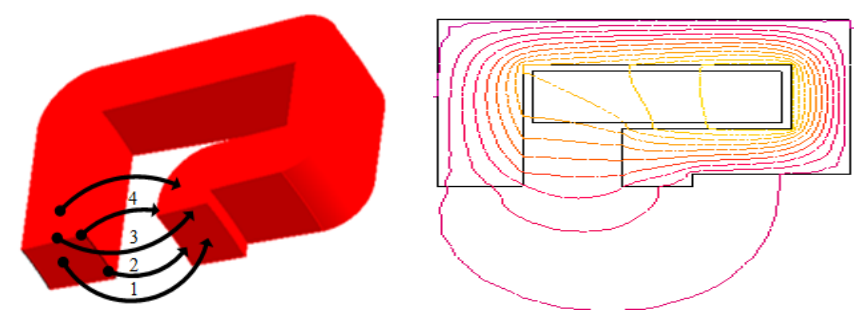

Fig. 8. Flux tubes showing the types of leakages in stator (left) compared with the FEA leakage flux tubes in Flux2D (right)

The possible flux paths through the air gap and the fringing paths around the air gap of the stator core [18] is numbered from 1 to 4 as shown in Fig. 8.

The semi-circular line number 1 denotes the fringing path between the two stator pole faces. Assuming that the fringing between the planes form a volume of half annulus, the reluctance of fringing between planes is given by

$$
\Re_{1}=\frac{\pi}{\mathrm{p} \mu_{\mathrm{o}}(r w 2) \log \frac{(0.5 \lg +\mathrm{hry})}{(0.5 \lg )}}
$$

The line number 2 denotes the fringing between the two vertically-aligned parallel edges forming a volume of a quadrant of a spherical shell [18]. The reluctance for fringing between these two parallel edges is given by

$$
\mathfrak{R}_{2}=\frac{4.34}{\mathrm{p} \mu_{\mathrm{o}}(\mathrm{rw} 2)}
$$

The line number 3 denotes the fringing between two aligned edges forming a volume of semicircular cylinder [18]. The fringing reluctance between two aligned edges can be approximated by

$$
\mathfrak{R}_{3} \approx \frac{4}{\mathrm{p} \mu_{\mathrm{o}} \mathrm{hry}}
$$

The line number 4 denotes the fringing between the corners of the pole faces forming a volume of spherical quadrant [18]. The fringing reluctance between corners can be approximated by

$$
\mathfrak{R}_{4} \approx \frac{6.5}{\mathrm{p} \mu_{\mathrm{o}}(0.5 \lg )}
$$

\section{E. Winding leakage}

By applying Biot-Savart law to the current carrying conductor, the flux $\varphi_{w}$, leaking the conductor can be determined as a function of the conductor radius $R_{c}$. The reluctance of the winding leakage $R_{w}$ given by

$$
\begin{gathered}
d \varphi_{w}=d B A_{\text {coil }} \\
\varphi_{w}=\int_{0}^{\frac{\pi}{3}} d \emptyset=\frac{\mu_{o} N I R}{12} \\
R_{w}=\frac{\varphi_{w}}{N I}
\end{gathered}
$$

where $A_{\text {coil }}$ is the cross-section area of the coil.

\section{NONLINEAR SOLUTION FOR THE MEC}

Magnetic saturation increase losses and degrades machine performance. Due to excessive simplifications, conventional MEC models often lack the ability to accurately predict the machine performance when the machine saturates at higher current. Correction factors based on experience may be used for compensation but it is not adaptable to changes in machine geometry. Thus a nonlinear model for the MEC is required to increase the accuracy of result estimation when the machine saturates. There are several methods for solving a set of non-linear equations e.g. Newton's and Gauss-Siedel methods. Newton's method requires Jacobian matrix calculation in which its elements are partial differential of reluctance with respect to flux. In this case, since reluctances are not explicit function of flux,

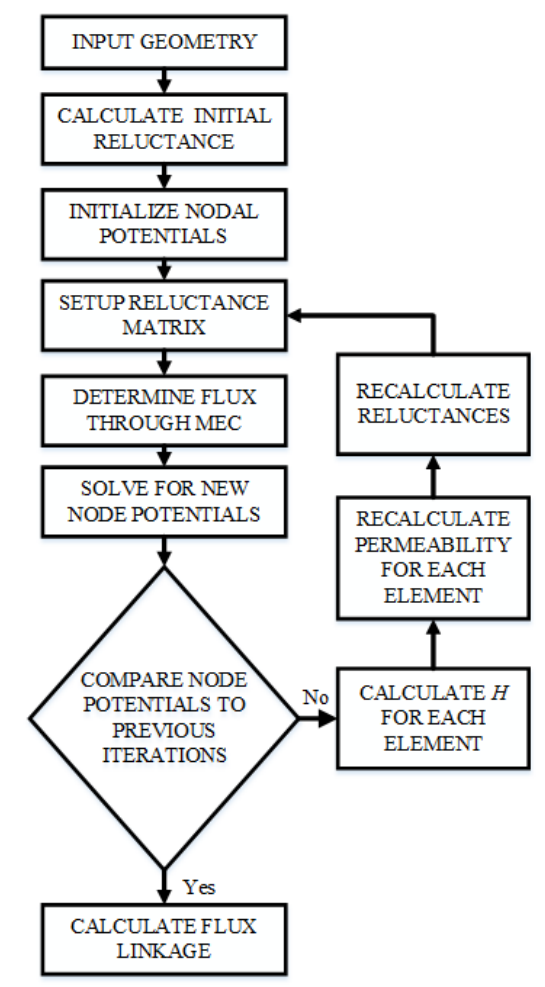

Fig. 9. Nonlinear analysis using Gauss-Siedel method. 
obtaining analytical expressions for Jacobian matrix elements is not possible. Therefore, a Gauss-Siedel method as shown in Fig. 9, with an accelerating factor of 300 for faster convergence has been used to solve the problem. The magnetic scalar potential drop across each reluctance element of the MEC model is calculated. The reluctance of the iron core elements changes as the machine begins to saturate. So an iterative approach is used to update the reluctance matrix when the $\mathrm{mmf}$ drop compared with previous iterations is within an acceptable error difference of magnitude $10^{-5}$.

\section{RESULTS}

The MEC and 3D FEA model was based on dimensions given in Table 1. The no-load flux linkage and EMF was determined for different rotor positions. Flux linkage and torque was also determined for different rotor positions while exciting the coil conductor with different values of current, testing for both saturated and non-saturated conditions.

\section{A. Flux linkage distribution and no-load EMF}

The MEC model was used to predict flux linkage under no-load condition at different rotor positions as shown in Fig. 10. Flux linkages at different rotor positions under current excitations - unsaturated (20A), partially saturated $(60 \mathrm{~A})$ and fully saturated $(100 \mathrm{~A})$ were shown in Fig. 11. For different current excitations (0-100A), flux linkages at partially aligned $\left(4^{\circ}\right)$ and completely unaligned $\left(6^{\circ}\right)$ pole positions are shown in Fig. 12 and Fig. 13 respectively. Noload EMF for different rotor positions is shown in Fig. 14. The results shows some discrepancy at higher currents due to magnetic saturation, however the error is below $5 \%$.

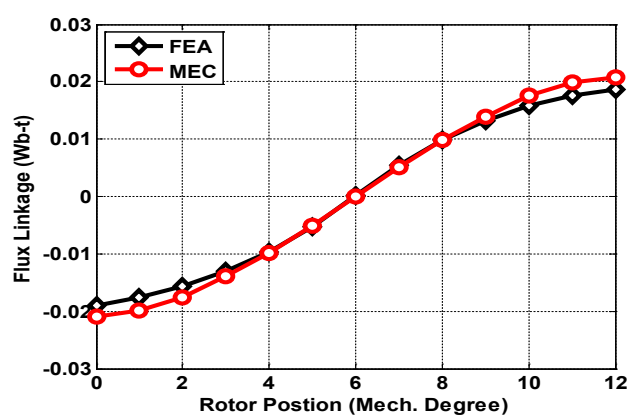

Fig. 10. Flux linkage at $0 \mathrm{~A}$

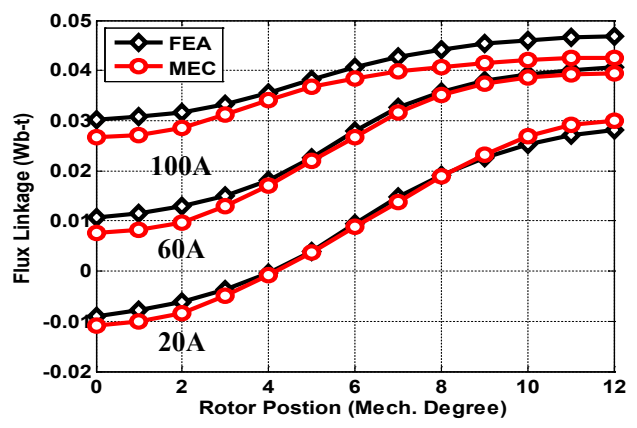

Fig. 11. Flux linkage at $100 \mathrm{~A}, 60 \mathrm{~A}$ and $20 \mathrm{~A}$

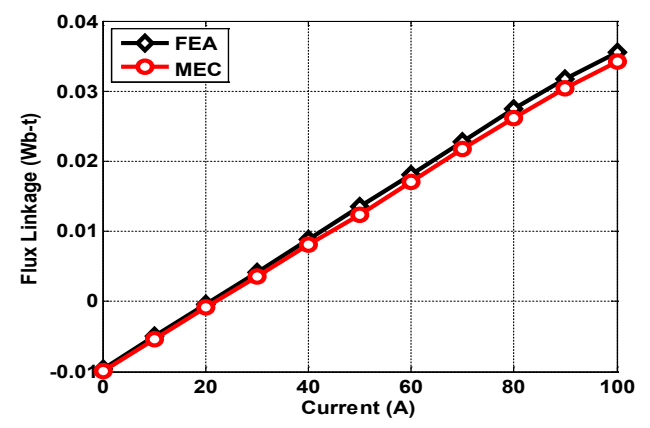

Fig. 12. Flux linkage at $4^{\circ}$ rotor position for currents 0-100 A

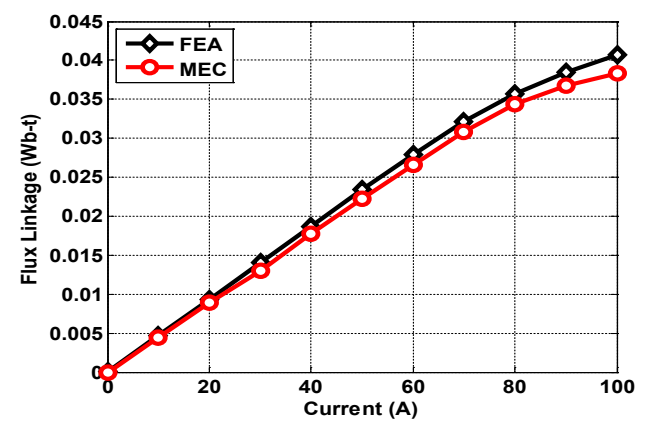

Fig. 13. Flux linkage at $6^{\circ}$ rotor position for currents $0-100 \mathrm{~A}$

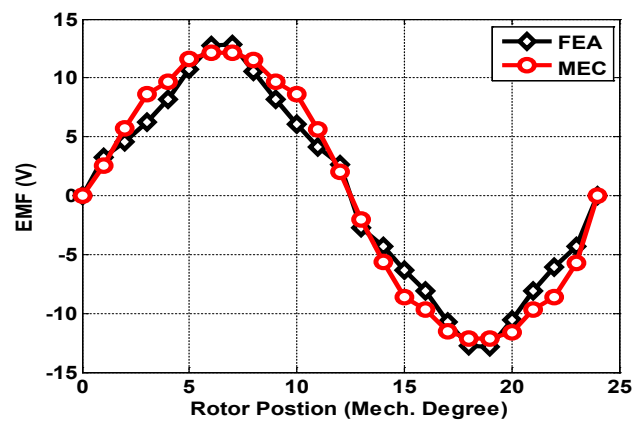

Fig. 14. No-load EMF

\section{B. Torque characteristics}

Torque was predicted using the virtual work method [22]. In Fig. 15, torque produced at different rotor positions for both unsaturated $(20 \mathrm{~A}, 60 \mathrm{~A})$ and saturated $(100 \mathrm{~A})$ cases are illustrated. Fig. 16 and Fig. 17 show the torque produced at different current excitations in partially aligned and completely unaligned pole positions respectively. Transient simulation was also conducted with the MEC-Simulink circuit simulator and compared with 3D FEA-Simulink coupled simulation. In the FEA-Simulink coupled simulation, the simulink circuit was used to regulate the sinusoidal current supplied to the 3D machine in Flux3D which provided the FEA torque. The generated torque from both simulations are shown in Fig. 18. At high currents when the machine saturates, there are some discrepancies in the average torque values. 


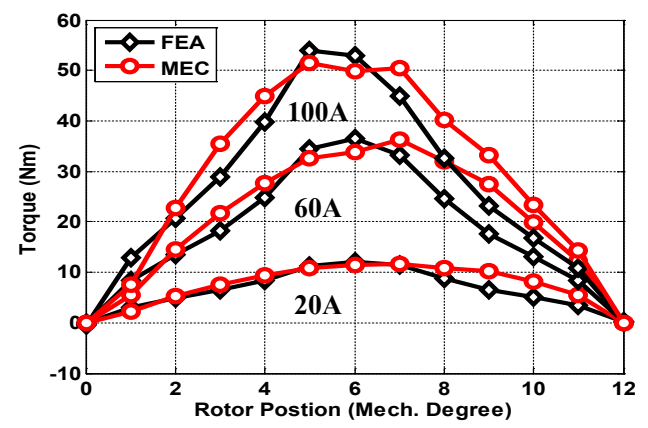

Fig. 15. Torque produced at $100 \mathrm{~A}, 60 \mathrm{~A}$ and $20 \mathrm{~A}$

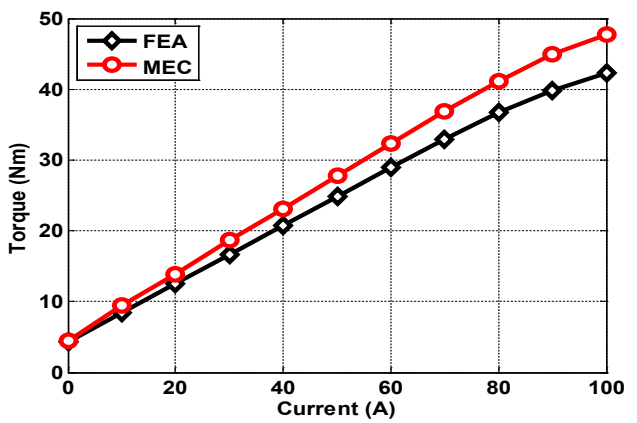

Fig. 16. Torque produced at $4^{\circ}$ rotor position for currents $0-100 \mathrm{~A}$.

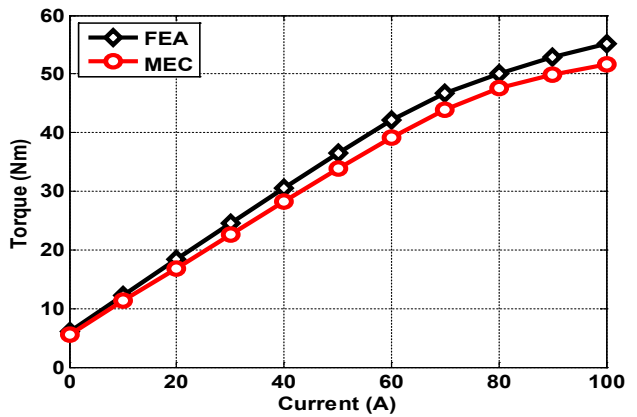

Fig. 17. Torque produced at $6^{\circ}$ rotor position for currents $0-100 \mathrm{~A}$

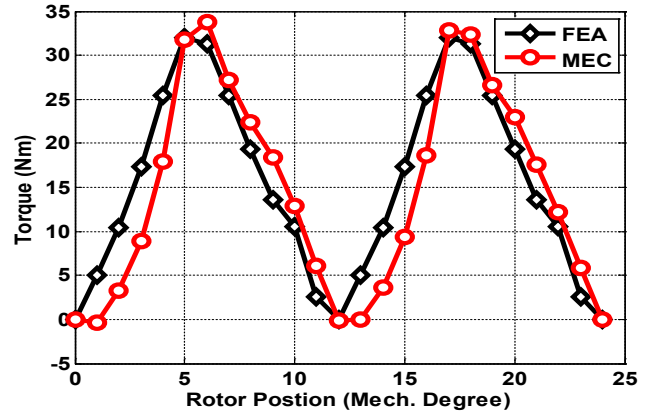

Fig. 18. Generated torque from transient MEC-Simulink and FEA-Simulink coupled simulation

\section{Changes in machine geometry}

The developed MEC model is capable of handling geometric parameter variation to predict the changes in average torque. The magnetic loading of the TFM is changed by altering the dimensions of the TFM rotor thickness and magnet length, and their effect on torque production is shown in Fig. 19 and Fig. 20 respectively.

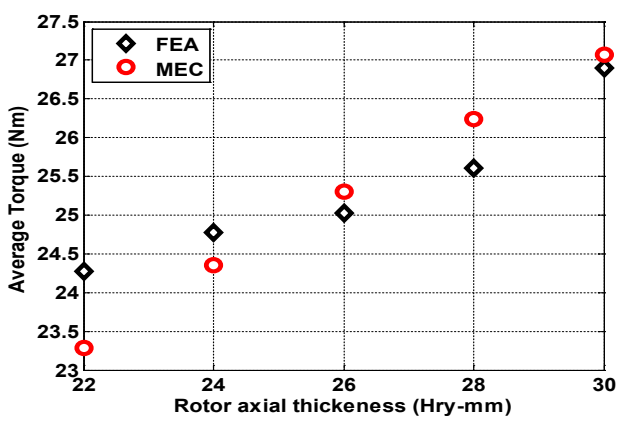

Fig. 19. Average torque for different values of rotor thickness

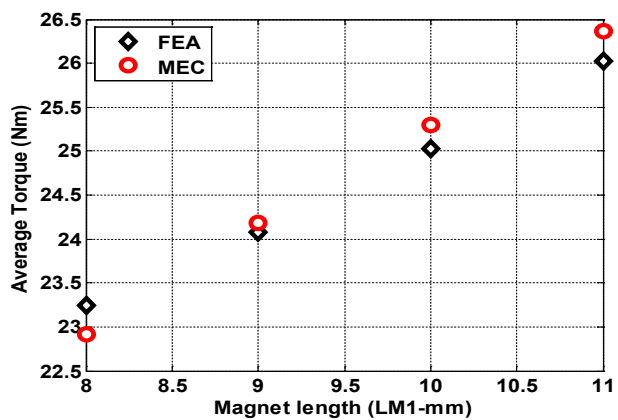

Fig. 20. Average torque for different values of magnet length

\section{CONCLUSION}

A single phase, $1 \mathrm{~kW}, 400 \mathrm{rpm}$ transverse flux machine (TFM) for use in wind power applications has been analytically modeled. The 3D model of the machine was developed using Flux 3D software. A dynamic analytical model for the machine was also developed using magnetic equivalent circuit (MEC) modeling that allowed dimensioning and performance analysis of the designed machine with reduced computational resources. The MEC modeling includes permanent magnet, rotor, stator, stator winding and air gap leakages and variable air gap reluctances. The MEC model was nonlinear and includes the effect of saturation which includes an iterative algorithm to calculate the reluctance of iron core elements as increasing current drove them into saturation. The flux linkage and torque generated by the machine were obtained analytically and verified with results obtained from Finite Element Analysis (FEA). The MEC model holds its merit under dimension and current variations. Transient simulation was also conducted with the MEC model where current regulation was done to obtain torque and regulated phase currents. Single phase 3D-FEA coupled simulation was also carried out to verify the results. The analytical MEC model provided estimates with less than 5\% error, while reducing the computation time by $1 / 25$, when compared with FEA based results.

\section{REFERENCES}

[1] W. M. Arshad, P. Thelin, T. Backstrom, and C. Sadarangani, "Use of Transverse-Flux Machines in a Free-Piston Generator," IEEE Trans. Ind. Appl., vol. 40, no. 4, pp. 1092-1100, July/August 2004. 
[2] W. M. Arshad, T. Backstrom, and C. Sadarangani, "Analytical design and analysis procedure for a transverse flux machine," Proc. IEEE Conf. Elec. Mach. and Drives, pp. 115-121, 2001.

[3] A. I. Mitcham, "Transverse flux motors far electric propulsion of ships," IEE Colloq. New Topologies Permanent Magnet Machines, pp.3/1-3/6, 1997.

[4] U. Werner, S. Hoffmann, J. Schüttler, M. Vinogradski, B. Orlik, "Stromregelung von Permanenterregten Transversalflussmotoren in Servo-Direktantriebsanwendungen," DFMRS, Feb 2006.

[5] K. T. Chau, M. Cheng, and C. C. Chan, "Nonlinear magnetic circuit analysis for a novel stator doubly fed doubly salient machine," IEEE Trans. Magn., vol. 38, no. 5, pp. 2382-2384, Sep. 2002.

[6] P. Campbell, "Magnetic circuit of an axial field dc electrical machine," IEEE Trans. Magn., vol. MAG-11, no. 5, pp. 1541-1543, Sep. 1975.

[7] J. D. Law, T. J. Busch, and T. A. Lipo, "Magnetic circuit modeling of the field regulated reluctance machine Part I: Model development," IEEE Trans. Energy Convers., vol. 11, no. 1, pp. 49-55, Mar. 1996.

[8] H. Polinder, J. G. Slootweg, M. J. Hoeijmakers, and J. C. Compter, "Modeling of a linear PM machine including magnetic saturation and end effects: Maximum force-to-current ratio," IEEE Trans. Ind. Appl., vol. 39, no. 6, pp. 1681-1688, Nov./Dec. 2003.

[9] M.F.J. Kremers, J.J.J. Paulides, J.L.G. Janssen, and E.A. Lomonova, "Analytical flux linkage and EMF calculation of a transverse flux machine," Proc. Int. Conf. on Electrical Machines (ICEM), pp. 2668-2673, 2014.

[10] P. Seibold, and N. Parspour, "Analytical computation method of transverse flux permanent magnet excited machines via nodal analysis," Proc. Int. Conf. on Electrical Machines (ICEM), pp. 410415, 2014.

[11] E. Pădurariu, K. Hameyer, L.E. Someşan, I.A. Viorel, and C. Marţiş, "A Simple Analytical Model of a Permanent Magnet Transverse Flux Motor with a Particular Disk Rotor," Proc. Int. Conf. on Optimization of Electrical and Electronic Equipment (OPTIM), pp. 641-646, 2012.

[12] M. Zafarani, M. Moallem, and A. Tabesh, "Analytical Model for a Transverse Flux Permanent Magnet Machine using Improved
Magnetic Equivalent Circuit Approach," Proc. Int. Conf. on Systems Engineering (ICSEng), pp. 96-99, 2011.

[13] Y. Kano, T. Kosaka, and N. Matsui, "A Simple Nonlinear Magnetic Analysis for Axial-Flux Permanent-Magnet Machines," IEEE Trans. Ind. Appl., vol. 57, no. 6, pp. 2124-2133, June 2010.

[14] D-K. Hong, B-C. Woo, D-H. Koo, and D-H. Kang, "Optimum Design of Transverse Flux Linear Motor for Weight Reduction and Improvement Thrust Force Using Response Surface Methodology," IEEE Trans. Ind. Appl., vol. 44, no. 11, pp. 4317-4320, November 2008.

[15] V. Ostovic, "Magnetic equivalent circuit presentation of electric machines," Electr. Machines Power Syst., vol. 12, no. 6, pp.407-432, 1988.

[16] V. Ostovic, "A simplified approach to magnetic equivalent-circuit modeling of induction machines". IEEE Trans. Ind. Appl. vol. 24, no. 2, pp.308-316, Mar/Apr 1988.

[17] M. Moallem, C. M. Ong, "Predicting the torque of a Switched Reluctance Machine from its Finite Element Field Solution ", IEEE Trans. On. Energy Conversion, vo1.5, No.4, Dec. 1990.

[18] H. C. Rotors, Electromagnetic Devices. New York:Wiley, 1941.

[19] K. Lu, P. O. Rasmussen, and E. Ritchie, "Design considerations of permanent magnet transverse flux machines," IEEE Trans. Magn., vol. 47, no. 10, pp. 2804-2807, 2011.

[20] M. Harris, G. H. Pajooman, and S. Abu Sharkh, "The problem of power factor in vrpm (transverse-flux) machines," Eighth International Conference on Electrical Machines and Drives, (Conf. Publ. No. 444), pp. 386-390, 1997.

[21] J. M. Kokernak and D. A. Torrey, "Magnetic circuit model for the mutually coupled switched-reluctance machine," IEEE Trans. Magn., vol. 36, no. 2, pp. 500-507, Mar 2000.

[22] J. L. Coulomb and G. Meunier, "Finite element implementation of virtual work principle for magnetic or electric force and torque computation," IEEE Trans. Magn., vol. 20, no. 5, Sept 1984.

[23] Y. Chen, Z.Q. Zhu, and D. Howe, "Three-dimensional lumpedparameter magnetic circuit analysis of single-phase flux-switching permanent-magnet motor," IEEE Trans. Ind. Appl. vol. 44, no. 6, pp.1701-1710, Nov/Dec 2008. 